POSTER

\title{
Allogeneic adipose -derived mesenchymal stem cell transplantion enhanced the expression of angiogenic factors on mouse acute hindlimb ischemia model
}

\author{
Ngoc Bich Vu, Ha Thi -Ngan Le, Thuy Thi-Thanh Dao, Lan Thi Phi, Phuc Van \\ Pham, Ngoc Kim Phan, Van Thanh Ta \\ Laboratory of Stem Cell Research and Application, \\ University of Science, Vietnam National University HCMC, Ho Chi Minh City, Vietnam
}

*For correspondence:

vbngoc@hcmus.edu.vn

Competing interests: The authors declare that no competing interests exist.

Received: 2017-03-18

Accepted: 2017-04-29

Published: 2017-09-05

Copyright The Author(s) 2017. This article is published with open access by BioMedPress (BMP).

This article is distributed under the terms of the Creative Commons Attribution License (CC-BY 4.0) which permits any use, distribution, and reproduction in any medium, provided the original author(s) and the source are credited.

\section{Abstract}

The cell migration and/or molecular mechanism in healing of damaged vascular or muscle tissue are emerging field with strong research interest worldwide. This study focuses on evaluating the role of allogennic adipose-derived mesenchymal stem cells (ADMSCs) in restoring damaged tissue through the migration of cells and the expression of genes related to myocyte regeneration and angiogenesis on hindlimb ischemic mouse model. ADMSCs were labeled with GFP (ADMSC-GFP). The proximal end of the femoral blood vessel of mice (over 6 months old) were ligated at 2 possition then cut between the two ties. Hindlimb ischemic mice were randomly divided to 2 groups. Group $1(n=36)$ was injected PBS $(100 \mu l)$, group $2(n=36)$ was transplanted ADMSC-GFP (106 cell/100 $\mu$ l PBS) near the cutting position. The migration of ADMSC-GFP in hindlimb was analyzed by UVVis system. The expression of genes related to angiogenesis and muscle tissue repairing was quantified by real time RT-PCR. Muscle tissue structure was histological analyzed by H\&E staining. The result showed that ADMSC existed in grafted hindlimb during 7 days. Grafted cells migrated to other damaged areas such as thighs and heels. Ischemic hindlimb were stimulated to increasing expression of several angiogeneic genes including Flt-1, Flk-1 Ang-2 in both group. Especially, the expression of Ang-2 and myogenic-related gene MyoD were significantly increased in ADMSC-treated group compared to non-treated group; and increased at 28th day compared to 3 rd day. The other factors such as HGF, CD31, Myf5, TGF- $\beta$ also expressed much more in ADMSC treated group than the another one. Muscle histological structure in ADMSC group were siminar the normal mouse after 28 day. Thus, grafted-ADMSC was able to migrate to other area in injured hindlimb, existed for about 7 days and have significant positive effects on stimulating the expression of myogenic and angiogenesis- related genes.

Biomed Res Ther 2017, 4(S)

DOI 10.15419/bmrat.v4iS.288 


\section{Keywords}

messenchymal stem cell, adipose tissue, hindlimb ischemia, angiogenesis, muscle cell regeneration

\section{Funding}

The university of Science, Vietnam National University, Ho Chi Minh city, Viet Nam under grant number T2016-20.

\section{References}

